Ana M. Cunha, Carlos H. Marcondes, Joyce Messa, Monnique S. P. A. Esteves, Nilson Theobald Barbosa, Rosana Portugal, Tatiana de Almeida [1]

\title{
Pronnsal of a general classification schema for museum objects
}

\begin{abstract}
The current schema used by the Rio de Janeiro`s Museum Network website to classify the museum objects in different museums' collections contains 16 categories that are no longer enough to encompass all the collections of museums about to adhere to the network. These new collections include scientific and intangible cultural heritage objects that needed to be fitted in categories of their own. In order to expand the classification schema, an Ontological approach was used, as well as the Aristothelic classification theory, to analyze and distinguish the different types of museum objects, define new categories and clarify the present ones, including them on the new broadened schema proposed, guaranteeing compatibility with museums already connected to the network. The categories suggested include a broader one, Museum objects, which contains Natural objects (subdivided in Inorganic and Organic objects) and Physical or conceptual products of human culture - Man-made objects (comprising Material culture objects or Artifacts and Conceptual products of human Culture - the first one containing all 16 pre-existing categories); and a new broad category for Cultural heritage objects. This proposal constructs a broader schema then the one in use, while encompassing it and allowing the insertion of any new categories that may appear in the future.
\end{abstract}

\section{Introduction}

The Web Museum Network of the state of Rio de Janeiro, Brazil, holds a website where users can search for records and images of museum objects available in different museum collections (http://www.museusdoestado.rj.gov.br/sisgam/). To support transversal searches over objects of the same type in different museum collections, the Web Museum Network uses a classification schema of broad object categories based on Ferrez and Bianchini (1987). This is a pioneering and established schema used in Brazilian museums, holding 16 categories: 1. Hunting and War, 2. Visual Arts, 3. Pecuniary objects (coins, etc), 4. Building, 5. Interior decoration objects, 6. Work, 7. Recreation, 8. Insignia, 9. Ceremonial objects, 10. Communication, 11. Transport, 12. Person al objects, 13. Penance and torture objects, 14. Measurement, recording, 15. Packing, 16. Samples, fragments. This schema is based on what a museum object is, its ontological nature. Although there are other specific facets by which museum objects may be classified as (type of material or technique, style, etc), these facets only do not apply to all existing categories of objects. The ontological facet is the most general and could be virtually applied to any museum collection to adhere to the Web Network. As the Web Network expands, by the adherence of several new museums holding scientific collections and intangible cultural heritage, it becomes necessary to expand the original schema to encompass the new categories of objects.

This paper addresses the following questions. How to update (reengineering) Ferrez and Bianchini's (1987) museum object classification schema to include categories such as those needed to integrate and classify scientific collections, and intangible cultural heritage objects comprising museum collections that adhere to the Web Network? What are the objects in Ferrez and Bianchini's museum object classification schema 
categories? Is there a category or categories that can subsume all or some of these categories? What is a museum object and in what general categories should it be subdivided? How to integrate the original the original Ferrez and Bianchini's museum object classification schema with such a general schema? How to integrate other museum thesaurus used in Brazil within the proposed general museum classification schema?

The objective of this paper is to propose a general museum objects classification schema that expands the original one proposed by Ferrez and Bianchini (1987) with the aim of support scientific collections and intangible cultural heritage objects, alongside the sixteen categories of the previous schema.

The paper is organized as follows: after this Introduction, section 2 presents methods and material used. Section 3 presents theoretical and methodological bases used. Section 4 presents the definitions collected and used as input to expand and complement the original classification schema. Section 5 presents and discussed the final classification schema. Section 6 presents the concluding remarks and future directions of research.

\section{Methods}

Literature and different museum classification schemas were used as sources for categories that could subsume the sixteen original ones and could hold both scientific and intangible cultural heritage collections. Definitions of museum object, artifact, natural objects, among others, were also collected. Definitions of intangible cultural heritage manifestations were collected from official documents concerning Brazilian policy for intangible cultural heritage (Cavalcanti \& Fonseca, 2008). These definitions were used as inputs to define classes of entities. Ontological analysis (Guarino and Welthy, 2000, 2009), conceptual definitions (Dahlberg, 1981, 1983) and Aristothelic classification theory were then used as methodology to analyze and distinguish the different types of museum objects in order to classify them into a unique general schema.

\section{Theoretical bases}

Ontology as a philosophical inquiry is the science of what is, of all kinds of beings, their properties and relations in all domains of reality. It aims at answering questions such as: What is? What types of entities exist? What are their differences, what are their similarities? (Welthy \& Smith, 2001, p. 2; Grenon \& Smith, 2004, p. 138; Guarino, 1997, p. 1).

Within the scope of Semantic Web, ontological analysis have been used as a tool to formally model the knowledge of different domains and record it in artifacts such as computational ontologies, thus enabling computers to reason on this knowledge.

Specifically ontological analysis seeks to identify "formal distinctions between the elements in a domain, independently of their actual reality" (Guarino, 1997, p. 1).

Accordingly, ontological analysis tries to answer the following questions concerning all aspects of reality or a specific domain: What is it? What types of entities exist? What are their differences, what are their similarities? What are the properties that define an entity to be this specific entity? What is the difference of essential properties, 
accidental properties and observed-relative properties? What is implicit of in an assumption that something exists? What makes something a whole, what makes it a part? What entities are independent, what are dependent, of what entities? When and under what conditions one entity begins to exist, evolves and ceases to exist? What entities precede the existence of other entities?

In order to answer these questions, ontological analysis uses theoretical and methodological tools, the meta-properties, which can be applied to the classes and relationships that comprise the taxonomic backbone of a knowledge organization system. These meta-properties are: Identity, Dependence, Essentiality and Integrality (Guarino \& Welthy, 2000, 2009). Of these meta-properties, Identity is the most important as, according to the definitions of museum object collected, we are dealing with objects that maintain a persistent identity throughout all their existence. We can build the backbone of the proposed schema by assigning properties that assure identity to their instances; these properties are the different object types.

Another relevant methodological and theoretical contribution to ontological analysis is Searle's (1995) theory of the process of social construction of reality, in which features of objects are socially attributed/added and became embedded within their essence.

Here ontological analysis was used to precisely identify what kind of entity is a museum object and within what types of entities could this class be subdivided, as we can see below:

Applied to the problems of knowledge organization this means that any entity with which we are

dealing ought to be understood and described 'according to extension and intension', in other words,

the concepts existing in our minds, books, text, and discourses are more or less concealed and must be

made explicit by adequate methods. (Dahlberg, 1992, 69).

To achieve this objective we seek for definitions of different museum objects. Dahlberg in his Referent-oriented, Analytical Concept Theory highlights the role of definitions in knowledge organization. She identifies three kinds of definitions, namely partitive, functional and generic. Generic definitions are building by declaring the "nearest genus" and the "differentiae" from this "genus", an essential and unique characteristic holding for the "differentiae" but not for the "genus". As a consequence an exclusive class may be defined by declaring the "nearest genus" and a property that do not hold for that "differentiae".

Since Aristotle (Berg, 1982) definitions are strongly related to classification. As stated by Dahlberg $(1981,19)$ :

If the genus proximum is said to be an essential characteristic, then it is also the genus proximum of

the genus proximum and so on until one reaches the ultimate category of a genus supremum and thus

creating a hierarchy of genera proxima.

A "genus supremum" is what Dahlberg considers "Form-categorial relationships [which] help to distinguish and define concepts according to their form classes of being Objects, Properties, Activities, Dimensions (space, time, position)”. (Dahlberg, 1992, 67).

Dahlberg (1981) suggests that, in order to construct concept systems, concept definitions within a domain must be collected, formalized or constructed and then used as inputs to systematization. 


\section{Definitions Collected}

The meaning of a term within a knowledge domain is established by a definition statement. Definitions can explicit characteristics, functions, constitutive elements of a term, thus delimiting its semantic in this specific context (Campos, 2010). Accordingly, different sources such as literature, specialized dictionaries and thesaurus were consulted, seeking for formal or informal definition, aiming to clearly define the meaning of the categories proposed as an extension of the original schema.

- Museum object

"the object-oriented methodology has recently received a good deal of attention among museologists.

This approach met considerable support within the International Committee for Museology. The museum object is considered to be the basic unit of the museum working procedures" (Van Mensh, 1992, 67).

"Museum objects are objects separated from their original (primary) context and transferred to a new, museum reality in order to document the reality from which they were separated." (Van Mensh, $1992,104)$.

"As documents museum objects (in the sense of primary museum material) are direct (authentic) witnesses of cultural and natural phenomena." (Van Mensh, 1992, 106).

Museum objects are "ontologically coincident with objects in general, but as to their semantic, they have a new function, i.e. the function of authentic witnesses, documents, and/or the testimony of natural and social facts" (Stransky 1985, 98).

Accordingly we can claim that museum objects have a dual nature, they are primary objects (natural or man-made) in addition to artifacts - descriptions of the primary object with the aim of adding a semantic function and enrich its role as documents and testimony of natural and social facts. As documents the characteristics assigned, added or highlighted are dependent on the natural or social relevance of the specific object, a curator choice. Therefore, due to the different types of museum objects, some characteristics are assigned to all types of objects, other just to some types. The object facet is one of those characteristics that may be assigned to all types of objects.

- Artifacts

Borgo and colleagues $(2009,1)$ define

$[\ldots]$ technical artifacts are objects that exist by human intervention; and that technical artifacts are to be contrasted to natural entities. Yet the perspectives are different in the way they spell out these

intuitions: the relevant human intervention may range from intentional selection to intentional production.

Hilpinen (2011) proposes a synthetic definition: "an artifact may be defined as an object that has been intentionally made or produced for a certain purpose".

Within the artifact category fit, with minor changes, the original sixteen categories of Museum Collections Thesaurus, thus assuring the compatibility with museums that already uses the old schema.

- Natural X Man-made objects

Encyclopaedia Britannica's definition of Life [1] is a clue to distinguish between natural objects and man-made ones: "Life, living matter and, as such, matter that shows certain attributes that include responsiveness, growth, metabolism, energy transformation, and reproduction". 
Baker's claim shows the relevance and the extension of Artifacts Category among museum objects. According to this author

Artifacts are objects intentionally made to serve a given purpose. The term 'artifact' applies to many different kinds of things - tools, documents, jewelry, scientific instruments, machines, furniture, and so on. Most generally, artifacts are contrasted with natural objects like rocks, trees, dogs, that are not made by human beings (or by higher primates). The category of artifact, as opposed to the category of natural object, includes sculptures, paintings, literary works and performances (Baker, 2004, 99).

Distinctions between natural objects and those made by man are also made by the CIDOC Conceptual Reference Model. Its hierarchy of classes makes an "a priori distinction" (Guarino, 1995, 5) from the class E 70 Thing and one of its subclass E71 Man-made Thing, which comprises "Everything that is not natural" (Oldman, \& Labs, CRM., 2014, 9). The British Museum Materials Thesaurus has as its three Top terms (or Categories): "Organic", "Inorganic" and "Processed Material[3]". The Art and Architectural Thesaurus, Getty Foundation[4], makes a distinction between Man-made objects and Natural objects.

Different knowledge organization systems make a clear differentiation between objects and processes (CIDOC CRM, 2013, SUMO[5[), or what is called continuants and occurents (BFO [6]), endurants and perdurants (THE WONDERWEB LIBRARY OF FOUNDATIONAL ONTOLOGIES, 2003), SNAP and SPAN (GRENON and SMITH, 2004). This differentiation concerns the modes of existence in time of entities. Objects are entities that maintain their identity during all their existence; processes happen during their existence. Processes are associated with, or depend on, objects. For example, the IALTA Conference at the end of World War II which decided the destiny of Europe, is a process. It has objects - actors - such as the prime minister of Soviet Union, Stalin, the prime minister of United Kingston, Churchill, and the president of United States, Roosevelt, as participants; and it occurred inside an object, a place, the city of Ialta, Crimea.

Once museum objects are separated from their original context, collected, guarded, preserved and exhibited with the intention of being testimonies of relevant natural and social phenomena during large periods of time without changing their properties, we can reasonably consider them as objects, or continuants, or endurants, or SNAP entities. Processes, as the historical process of Ialta Conference, however, due to their inherent temporal characteristics, can only be "musealized" if they are registered as objects, for example, by taking and preserving a photo of the Conference, or its proceedings.

- Intangible cultural heritage

According to UNESCO[7]:

Intangible or immaterial cultural heritage encompasses life expressions and traditions that communities, groups and people from all over the world inherit from their ancestors and pass their knowledge to their descendants. Besides sound and video recording, and archives, UNESCO considers that one of the most effective ways of preserving intangible heritage is to ensure that the bearers of this heritage can continue producing it and transmitting it".

UNESCO also enumerates different expressions of: "Intangible cultural heritage: oral traditions, performing arts, rituals[8]. 
In recent decades UNESCO enlarged the meaning of the term 'cultural heritage' beyond traditional monuments and object collections, including also

[...] traditions or living expressions inherited from our ancestors and passed on to our descendants, such as oral traditions, performing arts, social practices, rituals, festive events, knowledge and practices concerning nature and the universe or the knowledge and skills to produce traditional crafts[9]

\section{Results}

The most general category that subsumes all the other should be "Museum Object" which classical definition is based on musealization as a cultural and value-added process that separates an object from its original physical, functional and cultural context with the aim of representing or recording that aspect of the reality.

Subsumed to this general category are two other: Physical or conceptual products of human culture and Natural objects. To this last category are subsumed Organic objects, those which have their origin in living beings, and Inorganic object. These two categories will support history/natural history sciences museums and herbariums, etc. Within the Physical or Conceptual products of human culture category are the categories Material Culture Objects or Artifacts. Examining the scope notes and the subclasses of the original sixteen categories of Museum Collections Thesaurus is proposed that they fall, with minor changes, within this last category, thus assuring the compatibility with museums that already use the old schema. The new category Intangible cultural heritage, highlights in its definition the need to record these manifestations (Cavalcanti \& Fonseca, 2008); indeed, recording and documentation are prerequisite to the musealization of these manifestations.

The resulting schema can be presented as follows.

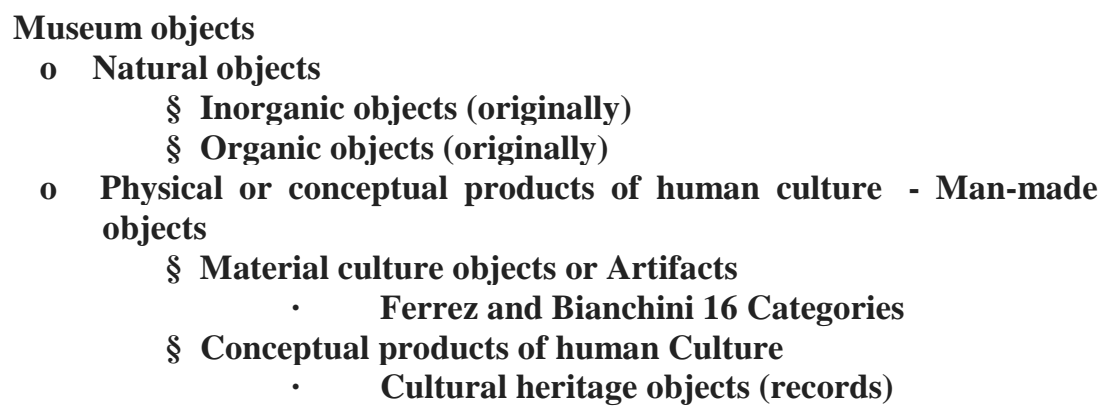

\section{Conclusion}

The resulting general schema inherits the object facet from Ferrez and Bianchini's schema as its systematization principle. Currently the object facet is a common facet to all museum object collections. This feature helps different thesaurus used by Brazilian museums to be integrated to the general schema by their respective object facets.

See, for example, the Tesauro de Cultura Material dos Índios no Brasil - Thesaurus of Brazilian Indigenous Material Culture (by its Artifact facet); the Thesaurus de Acervos Científicos em lingua portuguesa - Scientific Instruments Collections 
Thesaurus in Portuguese - (http://thesaurusonline.museus.ul.pt/hierarquica.aspx, by all of its Categories: scientific instruments, experiments and demonstration instruments, machines, reference objects, and utensil); and also the Tesauro de Folclore e Cultura Popular - Folclore and Popular Culture Thesaurus (http://www.cnfcp.gov.br/interna.php?ID_Secao=30) by its Artifact Categorie. The proposal here presented do not aims at being exhaustive but just to propose a broad schema that encompasses the old one by Ferrez and Bianchini (1987) and also any others that may be used by the new museums adhering to the Web Network, including different types of museum objects.

\section{References}

Baker, L. R. (2004). The Ontology of Artifacts. Philosophical Explorations, 7, 99-112. http://people.umass.edu/lrb/files/bak04ontM.pdf

Berg, J. (1982). Aristotle's theory of definition. ATTI del convegno internazionale di storia della logica,19-30. http://ontology.buffalo.edu/bio/berg.pdf

Bloom, P. (1996). Intention, history, and artifact concepts. Cognition, 60, 1-29. htttp://www.philosophy.dept.shef.ac.uk/hangseng/readinggroups/media/bloom.pdf Borgo, S., Franssen. M., Garbacz., P., Kitamura, Y., Mizoguchi R. \& Vermaas, P. E. (2014). Technical artifacts: An integrated perspective. Applied Ontology, 9, $217-$ 235. doi: 10.3233/978-1-60750-785-7-3

Borgo, S., \& Vieu, L. (2009). Artefacts in formal ontology. Handbook of philosophy of technology and engineering sciences, 273-308. ftp://ftp.irit.fr/IRIT/LILAC/

BV-HBPT09.pdf

British Museum Materials Thesauros. (1997). doi: htttp://www.collectionconstruct.org. uk/assets/thesaurus_bmm/matintro.htm.

Campos, M. L. de A. (2010). O papel das definições na pesquisa em ontologia. Perspectivas em Ciência da Informação, 15(1), 220-238. https://dx.doi.org/10.1590/S1413-99362010000100013

Cavalcanti, M. L. V. de C., \& Fonseca, M. C. L. (2008). Patrimônio imaterial

no Brasil: legislação e políticas estaduais. Brasília, Brazil: UNESCO.

http://unesdoc.unesco.org/images/0018/001808/180884POR.pdf

Oldman, D., \& Labs, C. R. M. (2014). The CIDOC Conceptual Reference Model (CIDOC-CRM): PRIMER.

CRM/sites/default/files/CRMPrimer_v1.1.pdf

Definition of the CIDOC Conceptual Reference Model, version 5.1.12. (2013).

http://www.cidoc-crm.org/docs/cidoc_crm_version_5.1.2.pdf

Cleland, C. E., Chyba, \& C. F. (2002). Origins of Life and Evolution of the Biosphere.

NASA's Astrobiology Magazine, 32, 387-393.

Dahlberg, I. Conceptual definitions for INTERCONCEPT. (1981). International

Classification, 8, 16-22.

Dahlberg, I. (1983). Terminological definitions: characteristics and demands. In:

Problémes de la définition et de la synonymie en terminologie. (pp.13-51).

Quebec, Canada: Girstern.

Ferrez, H. D., \& Bianchini, M. H. S. (1987). THESAURUS para acervos museológicos. Rio de Janeiro, Brazil: Fundação Nacional Pró-Memória. 
Grenon, P., \& Smith, B. (2004). SNAP and SPAN: Towards dynamic spatial ontology. Spatial cognition and computation. . 4, 69-104. htttp://ontology.

buffalo.edu/smith/articles/SNAP_SPAN.pdf

Guarino, N., \& Welty, C. (2000). Identity, unity, and individuality: Towards a formal toolkit for ontological analysis. Proccedings of the 14th European Conference on Artificial Inteligence. 219-223. Berlin, Germany: IOS Press. htttp://pdf. aminer.org/000/165/249/identity_unity_and_individuality_towards_a_formal_ toolkit_for_ontological.pdf

Guarino, N. \& Welty, C. A. (2009). An Overview of OntoClean. In: Handbook on ontologies (pp. 201-220). Berlin, Germany: Springer Berlin Heidelberg. http://www.loa.istc.cnr.it/Papers/GuarinoWeltyOntoCleanv3.pdf Hegenberg, L. (1974). Definições: termos técnicos e significado. São Paulo, Brazil: Cultrix.

Hilpinen, R. (2011). Artifact. In: E. N. Zalta (Ed.), The Stanford Encyclopedia of Phiilosophy. http://stanford.edu/archives/win2011/entries/artifact Van Mensch, P. (1992). Toward a methodology of museology. Unpublished Ph. D. dissertation. Zabreb, Croatia: University of Zagreb. http://xa.yimg.com/kq/groups/23466284/1995686355/name/Towards Miller, S. (2007). Artefacts and collective intentionality. Techné: Research in Philosophy and Technology, 11, 1-7. htttp://scholar.lib.vt.edu/ejournals/SPT/ v9n2/miller.html

Searle, J. (1995). The construction of social reality. New York, United States of America: The Free Press.

Thomasson, A. (2007). Artifacts and human concepts. In: S. Laurence and E. Margolis, (Eds), Creations of the mind: Theories of artifacts and their representation (pp.52- 73). Oxford, England: Oxford University Press.

THE WONDERWEB LIBRARY OF FOUNDATIONAL ONTOLOGIES. (2003). Preliminary Report. MASOLO, C., BORGO, S., GUARINO, N., OLTAMARI, A., SCHNEIDER, L. (Eds.). ISTR-CNR, Padova, Italy. http://wonderweb.semanticweb.org/deliverables/documents/D18.pdf.

\section{Notes:}

[1] This proposal was as a case study developed within a discipline of the Graduate Program of Information Science - PPGCI -, Federal Fluminense University, Rio de Janeiro. Brazil. in March 2015.

[2] Avalilable at: http://global.britannica.com/topic/life. Access Apr 212016.

[3] Avalilable at: http://www.collectionstrust.org.uk/assets/thesaurus_bmm/matintro.htm. Accessed Apr 21 2016.

[4] Avalilable at:http://www.getty.edu/research/tools/vocabularies/aat/. Accessed 23 Abr. 2016.

[5] Available at http://www.adampease.org/OP/. Accessed 13 May 2015.

[6] Available at http://ifomis.uni-saarland.de/bfo/. Accessed 13 May 2015

[7] Avalilable at:http://www.unesco.org/new/pt/brasilia/culture/world-heritage/intangible-heritage/. Accessed 23 Abr. 2016.

[8] Available at: http://www.unesco.org/new/en/culture/themes/illicit-trafficking-of-cultural-property/unescodatabase-of-national-cultural-heritage-laws/frequently-asked-questions/definition-of-the-cultural-heritage/.

Accessed 23 Abr. 2016. 
[9] Avalilable at: http://www.unesco.org/culture/ich/en/what-is-intangible-heritage-00003). Accessed 23 Abr. 2016.

Stransky, Z. (1985) 'Originals versus substitutes', in: V. Sofka ed., Originals and substitutes in museum. ICOFOM Study Series 9 (Stockholm) 95-102. 